\section{Attitudes towards older people among Swedish health care students and health care professionals working in elder care}

\author{
Gabriella Engström, ${ }^{1}$ Ingegerd Fagerberg ${ }^{2}$ \\ 1School of Health, Care and Social \\ Welfare, Mälardalen University, \\ Eskilstuna; ${ }^{2}$ Department of Health Care \\ Sciences, Ersta Sköndal University \\ College, and Department of \\ Neurobiology, Caring and Social Sciences, \\ Karolinska Institutet, Stockholm, Sweden
}

\section{Abstract}

The proportion of older people in the general population has increased and will continue to increase during the coming decade. Therefore, a positive attitude towards older people is important. The aim of the study was to gain knowledge about attitudes towards older people among health care students and health care staff in Swedish elder care settings. The study includes a convenience sample of 928 respondents comprised of health care students and three groups of professional caregivers [registered nurses (RNs) with university degrees, certified nursing assistants (CNAs), nurses] in a variety of health care settings in Sweden. The participants completed the Kogan's Old People (KOPS) Scale with 17 positive $\left(\mathrm{OP}^{+}\right)$and 17 negative $\left(\mathrm{OP}^{-}\right)$statements. The statements score ranged from 17 to 85 respectively. A significant $(\mathrm{P}<0.05)$ difference in both positive and negative scores was observed among the three professional caregiver groups. RNs had the highest positive score $\left(\mathrm{OP}^{+}: 64\right)$ as well as the lowest negative score (0P-:36). Health care students in semester one had the most unfavourable attitude toward older people (OP-:41) while students in semester two had the most favourable attitude toward older people $\left(\mathrm{OP}^{+}: 62\right)$. RNs reported both a higher positive score as well as lower negative score compared to nurses without an academic degree and CNAs. In addition, we found that progression in one's health care education contributes to reduce unfavourable attitudes toward older people. Health care professionals need to have the right skills to manage a more demanding role in the future in order to offer effective services for older people. A skilled workforce of health professionals is therefore very necessary.

\section{Introduction}

The proportion of older people in the Swedish population will increase from the current $17.8 \%$ to approximately $25 \%$ during the coming decade. ${ }^{1}$ These figures are in line with those reported across the western world. ${ }^{2}$ Older people are in good health for a longer period of time, yet as their health deteriorates, mainly due to multi-morbidity, ${ }^{3}$ their care needs will be more advanced and complex than earlier generations. In light of this trend, the problem of providing high quality care to older adults becomes urgent; attitudes toward elders will be an important element in this. Hence the need for further research to determine the attitudes of health care students as well as health care professionals towards this group.

With an increasing proportion of older people in the population, the number of physicians, physiotherapists, occupational therapists, registered nurses (RN), nurses without a bachelor degree and certified nursing assistants(CNA) who will provide care to them is also expected to rise. The Swedish Association of Local Authorities and Regions ${ }^{4}$ has concluded that there will be a shortage of registered nurses, physicians and well educated health care personnel in elder care in the future. To meet this challenge, it is important that education for health care professionals prepares students to provide high quality care for older people with multi-morbidity. Just as important as the students receiving a good education, is the possession of a positive attitude towards care recipients among professional caregivers within the field of care for older people.

\section{Literature review}

Previous studies have been concerned with the attitudes of health care students towards older people and their interests in working with older adults. ${ }^{5-9}$ These studies have largely been concerned with the attitudes of nursing students while the attitudes of other health care professionals, such as physicians, occupational therapists, social workers and physiotherapists, have not been focused upon. Against this backdrop, a study by Bernardini Zambrini et al. ${ }^{9}$ is interesting as they studied health care students from different disciplines at one university in Spain. The results revealed that students in psychology and physiotherapy were more interested in choosing geriatrics as their specialty while nursing students held the least positive attitudes towards the aged members of society. They also found that undergraduate students had less positive attitudes, a finding that contradicted results presented by Holroyd et al. ${ }^{8}$ who found that students' positive attitudes at the beginning of their education had become more negative at the end of their education.
Correspondence: Gabriella Engström, School of Health, Care and Social Welfare, Mälardalen University Box 325 SE-63105 Eskilstuna, Sweden. Fax: +46.0.16.153740.

E-mail: gabriella.engstrom@mdh.se

Key words: Kogan's old people scale, attitudes, hHealth care students, professional caregiver, older people.

Acknowledgements: this research was supported by funding from MagnusBergvalls Stiftelse, Sweden. The authors wish to thank all the professional caregivers and health care students who participated in the study.

Contributions: the authors contributed equally to the study design, in data collection, analysis and manuscript preparation.

Conflict of interest: the authors report no conflicts of interest.

Received for publication: 30 January 2011. Accepted for publication: 23 March 2011.

This work is licensed under a Creative Commons Attribution 3.0 License (by-nc 3.0).

(C) Copyright G. Engström and I. Fagerberg., 2011 Licensee PAGEPress, Italy

Nursing Reports 2011; 1:e2

doi:10.4081/nursrep.2011.e2

Deschodt et al. ${ }^{5}$ suggest that the amount of gerontological care in the curriculum is important in order to promote and foster positive attitudes towards the old. They suggest that gerontological care should be integrated into different subjects, something Fagerberg \& Gilje ${ }^{10}$ strongly disagreed with in their study of nursing education in Sweden and the USA. Cheong et al. ${ }^{6}$ underline the importance of a solid geriatrics element in education for medical students in order promote both an interest in and an understanding of the health problems that older people face. McCarry et al. ${ }^{7}$ among others, highlight the importance of clinical placements during a student's education, and in particular the views and attitudes promoted there towards the old and their care. This underlines the important role played by health care professionals supervising students working with older people in geriatric clinics, nursing homes and residential homes. There seems to be scarce research available about the attitudes health care professionals hold in relation to their care recipients. However, Gallagher et al. ${ }^{11}$ found that staff with a low educational level held negative attitudes towards older people compared to health care professionals with a higher education. The authors conclude that education is important in order to raise the level of knowledge and understanding of the social and health care problems older people might have. Interestingly, a major- 
ity of studies seem to be more concerned with the attitudes of professional caregivers in acute care settings toward the old, more specifically people with dementia or other cognitive impairments, ${ }^{12}$ or about the risk of developing work related stress and burnout. ${ }^{13}$

There is growing awareness that the health care sector must compete with other sectors in order to attract well-educated caregivers who want to work for them. Today, in Sweden, ${ }^{4}$ as well as in other European countries, ${ }^{14}$ the USA ${ }^{15}$ and Asia, ${ }^{16}$ less than $70 \%$ of all caregivers employed in care for older people have a formal education related to their work. Further research is needed to help us understand how to develop strategies to support caregivers who are committed to their work, are able to meet the needs of the old and have positive attitudes towards them. In a review of the literature, the preponderance of international research suggests that working with older people carries with it a low status ${ }^{11}$ and those who do work with care of older people are questioned as to whether or not they should apply for more promising work options. Studies also suggest that social attitudes towards a specific specialty area within health care are important as they influence future career choices. ${ }^{17,18}$ Therefore, a challenge for the future is to alter the often negative attitudes towards older people.

In order to provide good care for older people, a well-educated health care work force with positive attitudes towards the old is required. More research is needed to identify attitudes towards older people among different health care professionals in different disciplines and among health care students at different stages in their education. Therefore a study was conducted to contribute to this identified knowledge gap.

\section{The study}

\section{Aim}

The aim of the study was to gain knowledge about the attitudes towards older people among health care students and health care staff in Swedish elder care settings.

\section{Materials and Methods}

\section{Study design and participants}

A survey design was used to address the study aim. Self-adminstered questionnaires were distributed during the autumn of 2010 to a variety of health care professionals in health care settings for older people and to a variety of healthcare students at four out of the six health universities in two different counties in Sweden. A convenience sample of 928 respondents comprised of health care students, regis- tered nurses (RN with a bachelor degree), nurses (no academic degree) and certified nursing assistants (CNA with the responsibilities for duties such as obtaining and recording patient vital signs, toileting, and bathing) participated in the study. Permission to gain access to potential participants was facilitated by course leaders for the health care students and by the leaders at the health facilities for the professional caregivers. The course leaders and the leaders at the health facilities distributed the questionnaires to the students and professional caregivers. In addition to the questionnaires, all participants received a cover letter explaining the purpose of the study and information on how the data would be stored in a secured database. The participants voluntarily and anonymously answered the questionnaire items and returned the questionnaires via mailboxes placed in the health care settings or at the universities.

\section{Survey questionnaire}

All participants were asked to complete the self-administered questionnaire, the Swedish version of the Kogan's Old People Scale (KOPS) questionnaire. ${ }^{19}$ Participants were also asked to complete a form containing a number of demographic questions related to their profession, age, as well as if and for how long they had been working in the field of care for older people.

The KOPS is a 34 item questionnaire that was developed by $\operatorname{Kogan}^{20}$ as an indicator of attitudes towards older people for those that work within the field of care of older people. The KOPS has been translated into several languages, ${ }^{21,22}$ including Swedish. ${ }^{19}$ The questionnaire consists of 17 positive $\left(\mathrm{OP}^{+}\right)$statements and 17 negative $\left(\mathrm{OP}^{-}\right)$statements and uses a five-point Likert scale with response options on both the positive and negative statements ranging from strongly agree to strongly disagree. The positive and negative statements scores range from 17 to 85 respectively. The positive and negative statements are randomly ordered on the questionnaire. To obtain a positive score, the summing up of the positive answers is calculated separately from the negative ones. A higher score on the positive scale indicates a favourable attitude toward older adults. Before calculation the negative score, the negative statements are reversed which contribute to a higher score on the negative scale indicates an unfavourable attitude toward older adults. A total score ranging from 34 to 170 is obtained by adding the scores from both the 17 positive statements and 17 negative statements. Internal consistency for the whole KOPS instrument has been found to be $0.79 .{ }^{19,20}$ For the positive and negative statements, the internal consistency statements range from 0.66 to 0.77 and from 0.73 to 0.83 , respectively. ${ }^{19,23}$

\section{Statistical analysis}

All statistical analysis was performed using SPSS (statistical package of social science), version 17.0. A $\mathrm{P}<0.05$ was considered significant. When participants failed to answer one or two items on the KOPS, values for these items were imputed from the mean of scored items. Those with three or more missing variables were dropped from the study and excluded from the analysis. Kruskal-Wallis tests for ordinal data were conducted to compare differences between several independent groups (based on profession, age, work experience and length of education) on the KOPS. MannWhitney U- tests were conducted to compare two independent conditions: being in the professional category group and being in the health care students group. Mann-Whitney Utests also have been conducted to compare the performance groups within each category.

\section{Ethical considerations}

The study was approved by the ethic committees in the two counties.

\section{Results}

In total, 928 individuals answered the questionnaire. One hundred and twenty eight individuals were dropped from the study due to missing data on more than two items on the KOPS, ten individuals were dropped due to missing or unclear information regarding their occupation, and 26 additional individuals, one physician and 25 other health care professionals, were dropped due to relatively small numbers representing these groups. This left 764 questionnaires to analyze. The final sample for analysis included $72 \mathrm{RNs}$ with university degrees (9.5\%), 117 nurses (15\%), 50 CNAs (6.5\%) and 525 (69\%) health care students (including medical students, physiotherapist students, nursing students and students in different master's degree programmes, etc. psychiatric care, gerontological care, and primary health care).

The average age of the sample as a whole was $31.8(\mathrm{SD}=12.2)$, with a range of 17 to 67 . The health care students were the youngest $(\mathrm{M}=26.5, \mathrm{SD}=12.2)$ and the RNs were the oldest $(\mathrm{M}=44.7 \mathrm{SD}=12.9)$. The nurse's mean age was $44.0(\mathrm{SD}=12.2)$. The mean age of the CNAs was 43.2 ( $\mathrm{SD}=12.9)$. Among the professional caregivers, nurses had the greatest number of months of work experience $(\mathrm{M}=173.6, \mathrm{SD}=112.4)$ and the RNs the least $(\mathrm{M}=153.6, \mathrm{SD}=126.3)$. CNAs had an average of 160.6 months of work experience ( $\mathrm{SD}=132.2$ ).

The Kruskal-Wallis test for ordinal data indicated that there was a significant difference in positive scores and negative scores across the 
three professional category groups. RNs had the highest median positive score and the lowest median negative score. Regarding age groups, a significant difference was observed for the positive score. Professional caregivers older than 51 years had the highest median positive score. Furthermore, a significant difference in the negative score was observed across the four work experience groups. Professional caregivers with a work experience $>21$ years had the lowest median negative score, whereas caregivers with work experience of six to ten years had the highest median negative score (Table 1). Concerning health care students, the Kruskal-Wallis test indicated a significant difference in positive score and negative score across the groups. Students in semester two had the highest median positive score while students in semester one and four to seven had the lowest median negative score. Furthermore, a significant difference in median negative score was observed across the four groups for stage of education. Students in semester two and semester four to seven had the lowest median negative score, whereas students in semester one had the highest median negative score. Regarding age groups, a significant difference was observed for positive score and negative score. Health care students who were 31 years and older had the highest median positive score while students in the age group 2530 years and 24 or younger had a lower median positive score. The highest median negative score was observed for health care students 24 years or younger, with a median score of 39 , while students in the age groups $25-30$ years and 31 years or older had a median score of 37 (Table 2).

Using a Mann-Whitney U-test to compare the professional group with health care students yielded a significant difference in positive score $(\mathrm{P}=0.005)$ and total score $(\mathrm{P}<0.001)$. RNs reported a higher positive score compared to CNAs and nurses. No significant differences in the positive score between CNAs and nurses were found $(\mathrm{P}=0.765)$. Regarding work experience, individuals who had worked $\geq 21$ years in health care settings were more positive than individuals with less work experience. An analysis by occupational category revealed no significant differences between RNs $(\mathrm{P}=0.317)$ or CNAs $(\mathrm{P}=0.257)$. Nurses with $>21$ years of work experience showed a higher positive score compared to their colleagues who had worked for a shorter period of time $(\mathrm{P}=0.008)$.

\section{Discussion}

The findings of this study shed light on professional caregivers' and health care students' attitudes toward older people. Several studies among nursing students, medical students and health caregivers have noted negative attitudes toward older people. ${ }^{6,24,25}$ The key finding emerging from this study was the RNs' high positive attitudes as well as the low negative attitudes toward older people. RNs reported a higher positive score compared to both nurses and CNAs. These results confirm those of other authors ${ }^{22,23,26,27}$ who demonstrate that a higher level of education and the age of respondents relate to positive attitudes toward older persons and therefore, preferences for working within the field of elder care are likely to increase. One possible explanation for the high positive attitude as well as the low negative attitude among RNs may be that baccalaureate nursing programs in Sweden have aimed to provide stand-alone courses in gerontological care in recent years. ${ }^{10}$ If this is the case, stand-alone courses in gerontological care are needed for all professional caregivers. ${ }^{10,28}$ Integrating gerontological care into other sub-

jects, as Deschodt et al. ${ }^{5}$ suggest, runs the risk of giving responsibility for these courses to instructors who do not have sufficient knowledge in gerontological care. As such, they might have neither an interest in, nor an understanding of, the complexity and importance of the subject and thus cannot promote understanding, guide the students in their learning, nor be equipped to answer all the questions posed to them. In the worst case, teachers who themselves hold negative attitudes toward the old can be responsible for students' learning. A critical issue in nursing care for older people concerns the presence of caregivers who do not have formal education related to their work. Today, older people often present with complex problems and require higher levels of nursing care given by qualified and well educated health care personnel. However, more than $30 \%$ of the caregivers employed in care for older people have no formal education today. ${ }^{4,14-16}$ In order to offer high quality and

Table 1. Positive score, negative score and total score across professional category, age and work experience groups.

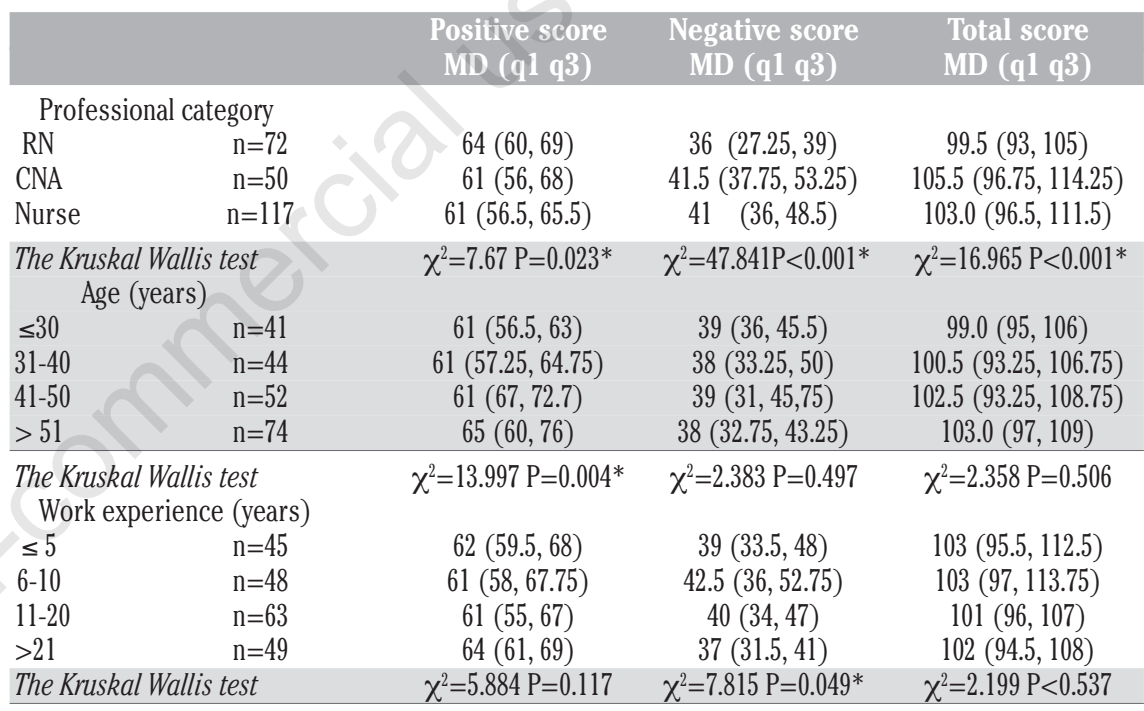

$* \mathrm{P}<0.05$; MD, median; $q 1$, first quartile; $q 3$, third quartile.

Table 2. Positive score, negative score and total score across length of education and age groups.

\begin{tabular}{|c|c|c|c|c|}
\hline & & $\begin{array}{l}\text { Positive score } \\
\text { MD (q1 q } 3 \text { ) }\end{array}$ & $\begin{array}{l}\text { Negative score } \\
\text { MD (q1 q3) }\end{array}$ & $\begin{array}{l}\text { Total score } \\
\text { MD (q1 q3) }\end{array}$ \\
\hline \multicolumn{5}{|c|}{ Length of education(Semester) } \\
\hline 1 & $\mathrm{n}=110$ & $60(55,64)$ & $41(36,46)$ & $100(96,106)$ \\
\hline & $\mathrm{n}=166$ & $62(57,66)$ & $37(32,43)$ & $99(93,104)$ \\
\hline & $\mathrm{n}=109$ & $61(58,65)$ & $39.5(35,45.75)$ & $101(95,106)$ \\
\hline & $\mathrm{n}=150$ & $60(57,63)$ & $37(32,42)$ & $97(91,102)$ \\
\hline \multicolumn{2}{|c|}{$\begin{array}{c}\text { The Kruskal Wallis test } \\
\text { Age (year) }\end{array}$} & $\chi^{2}=10.714 \mathrm{P}=0.013^{*}$ & $\chi^{2}=21.252 \mathrm{P}<0.001^{*}$ & $\chi^{2}=21.119 P<0.001^{*}$ \\
\hline$<24$ & $\mathrm{n}=288$ & $61(56.25,64)$ & $39(33.25,44)$ & $99(93,104)$ \\
\hline $25-30$ & $\mathrm{n}=118$ & $61(57,64)$ & $37(33,41.25)$ & $98(93.75,102)$ \\
\hline$\geq 31$ & $\mathrm{n}=119$ & $62(58,66)$ & $37(32,44)$ & $100(93,106)$ \\
\hline \multicolumn{2}{|c|}{ The Kruskal Wallis test } & $\chi^{2}=10.754 \mathrm{P}=0.004^{*}$ & $\chi^{2}=6.441 \mathrm{P}=0.042^{*}$ & $\chi^{2}=3.399 \mathrm{P}=0.176$ \\
\hline
\end{tabular}

${ }^{*} \mathrm{P}<0.05 ; \mathrm{MD}$, median; q1, first quartile; $\mathrm{q} 3$, third quartile. 
effective nursing care to those with a great need, a well-educated workforce is important.

Long term experience as a professional caregiver within the field of care for older people is related to the greater age of the caregiver. Our results show that professional caregivers $>51$ years of age held the most favourable attitude toward older people and toward work within the field of care for older people. At the same time, caregivers with at least 21 years of experience of care for older people reported the least unfavourable attitude toward older people and toward work within this field of care. Nelsson ${ }^{29}$ has put forth that middle- aged adults seem to have relatively positive attitudes towards older persons since they are getting older themselves and therefore are closer to becoming a member of the group older persons. Lu et al. ${ }^{30}$ also found that men and women aged 60-74 years have the same attitudes towards older people as those over 75 years of age. Perhaps professional caregivers who have reached middle age have fewer reasons to contribute to ageism than younger caregivers.

In contrast with other studies ${ }^{6,7,23,24}$ this study includes the attitudes of students from various health care programs and courses at different universities. Although it is plausible that differences in attitudes exist between these different groups, comparisons between the groups were not carried out. Following graduation, the participants will work as a team albeit in different professional roles, bringing with them the special set of knowledge and skills associated with their discipline. Collaboration among all professionals involved with the care is needed and a positive coherent attitude towards older people among health care teams is essential to promote, maintain or restore health while reducing the effects of illness. All health care students regardless of education must be educated in the needs and rights of older people in order to promote good care. ${ }^{31,32}$

In line with other studies ${ }^{24,33}$ the results show that health care students at the beginning of their education reported negative attitudes towards older people. As students in this study progressed through semester two their negative attitude scores decreased as to the same level as that of those who were at the end of their education. These negative attitudes among those at the start of their education may reflect the fact that they have no or little experience of older people. Negative attitudes are likely to increase if students do not know how to cope with situations they are exposed to. The amount of theoretical education in gerontological care and geriatrics will probably also have effects on the students' attitudes towards older people. ${ }^{10}$ In this study, as well as in Söderhamn et al. ${ }^{23}$ older health care students reported higher positive attitudes towards older persons than younger students. Since this study includes a variety of healthcare students in semester one to seven at different universities, and because the theoretical and clinical education associated with gerontological care varied across the programs with respect to the number of weeks of teaching and during which semester the education was given, no comparisons between the semesters were carried out.

\section{Limitations of the study}

KOPS was used, and the findings of this study contribute to knowledge of health care professionals' as well as health care students' attitudes towards older people.

The strength of the present study is the size and range of the sample. The study includes professional caregivers spread out between metropolitan, urban and rural areas and in contrast with other studies, ${ }^{6,7,24,25}$ this study includes students from various health care programs and courses at different universities. However, the study was a convenience sample and we cannot exclude the possibility that students and caregivers who did not respond biased the study results in some direction. It is possible that students and caregivers with their own experiences of older persons found the questions relevant and were therefore more likely to respond. On the other hand, students and caregivers with no experience of older persons may have chosen not to answer the questionnaires because of a lack of interests. The use of random sampling might have improved the generalizability of the results to the general population of healthcare students and professional caregivers who provide care to older people in Sweden.

KOPS has been translated into several languages and is used worldwide, but the scale was introduced 50 years ago. 0 ver this half century, social attitudes have developed, and the health care sector and health education have undergone critical changes. Therefore new attitude scales that are adjusted to today's context are crucial to attaining a more accurate understanding of the factors that contribute to or reduce age prejudice. Continued qualitative research is also necessary to understand both professional caregivers' as well as healthcare students' attitudes in order to develop gerontological courses or programs at universities.

\section{Implications for practice}

The findings have implications for: developing strategies for workforce planning, encouraging educators to increase the amount of gerontological care in the curriculum and for build and develop knowledge of actions and methods to improve positive attitudes towards the old and for building and developing knowledge of actions and methods to improve positive attitudes towards the old.

\section{Conclusions}

RNs reported both a higher positive score as well as lower negative score compared to nurses without an academic degree and CNAs. In addition, we found that progression in one's health care education contributes to reduce unfavourable attitudes toward older people. Health care professionals need to have the right skills to manage a more demanding role in the future in order to offer effective services for older people, a skilled workforce of health professionals is therefore very necessary.

\section{References}

1. SCB. Sveriges framtida befolkning: Beräkningar för åren 2009-2110. Stockholm: Statistiska Centralbyrån; 2009.

2. World Health Organization. Available from: http://www.who.int/healthinfo/statistics/m ortality_life_tables/en/. Accessed: Aug 11, 2010.

3. Fortin M, Lapointe L, Hudon C, et al. Multimorbidity and quality of life in primary care: systematic review. Health Qual of Life Outcomes 2004;2:51.

4. SVeriges kommuner och landsting. Aktuellt på äldreområdet. Stockholm: SVeriges kommuner och landsting; 2008.

5. Deschodt M, de Casterlé BD, Milisen K. Gerontological care in nursing education programmes. J Adv Nurs 2010;66:139-48.

6. Cheong SK, Wong TY, Koh GC. Attitudes towards the elderly among Singapore medical students. Ann Acad Med Singapore 2009;38:857-61.

7. McCarry J, Anbeeluck A, Simpson C, Williams G. Nursing students' experiences care. Nurs Old People 2009;21:16-22.

8. Holroyd A, Dahlke S, Fehr C, et al. Attitudes toward aging: implications for a caring profession. J Nurs Educ 2009;48: 374-80.

9. Bernardini Zambrini DA, Moraru M, Hanna M, et al. Attitudes towards the elderly among students of health care related studies at the University of Salamanca, Spain. J Contin Educ Health Prof 2008;28: 86-90.

10. Fagerberg I, Gilje F. A comparison of curricular approaches of care of the aged in Swedish and US nursing programs. Nurse Educ Pract 2007;7:358-64.

11. Gallagher S, Bennet KM, Halford JC. A comparison of acute and long-term healthcare personnel's attitudes towards older adults. Int J Nurs Pract 2006;12:273-9.

12. Arvanti A, Samakouri M, Kalamara E, et al. Health service staffs' attitudes towards 
patients with mental illness. Soc Psychiatry Psychiatr Epidemiol 2009;44: $658-65$.

13. Gustafsson G, Strandberg G. Meanings of staying healthy in a context where others developed burnout - phenomenologicalhermeneutic interpretation of healthcare personnel's narratives. Scand J Caring Sci 2008;23:456-64.

14. Nordenfelt L. Dignity in care of older people. Oxford: Wiley-Blackwell; 2009.

15. Voelker R. IOM: Focus on care for aging population. JAMA 2008;299:2611-3.

16. DeGuzman A, Coronel RDV, Chua KO, et al. The success and struggles for Filipino geriatric nurses in nursing homes. Educational Gerontology 2009;35:358-77.

17. Happell B, Brooker J. Who will look after my grandmother? Attitudes of student nurses towards the care of older adults. $\mathrm{J}$ Gerontol Nurs 2001;27:12-7.

18. Rognstad MK, Aasland 0, Granum V. How do nursing students regard their future career? Career preferences in the postmodern society. Nurse Educ Today 2004; 24:493-500.

19. Lindencrona C. Kontinuitet I omvårdnadenaväldrepatienter. Studier iutskrivningfrånsjukhus till hemmetsamtattityder till äldre bland sjuksköterskor. Disserta- tions from the Faculty of Medicine, Uppsala University, Sweden. Almqvist\&Wiksell International, Stockholm;1987.

20. Kogan N. Attitudes toward old people: the development of a scale and an examination of correlates. J Abnorm Soc Psychol 1961;62:44-54

21. Yen $\mathrm{CH}$, Liao WC, Chen YR, et al. A Chinese version of Kogan's Attitude Toward Older People Scale: reliability and validity assessment. Int J Nurs Stud 2009; 46:37-43.

22. Lambrinou E, Sourtzi P, Kalokerinou A,Lemonidou C. Reliability and validity of the Greek version of Kogan's Old People Scale. J Clin Nurs 2005;14:1241-7.

23. Söderhamn 0, Lindencrona C, Gustavsson SM. Attitudes towards older people among nursing students and registered nurses in Sweden. Nurse Educ Today 2001;21:225-9.

24. Hweidi IM, Al-Obeisat SM. Jordanian nursing students' attitudes toward the elderly. Nurse Educ Today 2006;26:23-30.

25. Lovell M. Caring for the elderly: changing perceptions and attitudes. J Vasc Nurs 2006;24:22-6.

26. Rogan F, Wyllie A. Engaging undergraduate nursing students in the care of elderly residents in Australian nursing homes.
Nurse Educ Pract 2003;3:95-103.

27. Herdman E. Challenging the discourses of nursing ageism. Int J Nurs Stud 2002; 39:105-14

28. Wallace M, Lange J, Grossman S. Isolation followed by integration: a model for development of a separate geriatric course. J Nurs Educ 2005;44:253-6.

29. Nelsson, TD. Ageism, stereotyping and prejudice against older persons. Massachusetts Institute of Technology, Massachusetts, USA; 2002.

30. Lu L, Kao SF, Hsieh YH. Positive attitudes toward older people and well-being among Chinese community older adults. J Appl Gerontol 2010:29;622-39.

31. Gustafsson C, Asp M, Fagerberg I. Municipal night nurses' experience of the meaning of caring. Nurs Ethics 2009;16: 599-612.

32. Gustafsson C, Asp M, Fagerberg I. Reflection in night nursing: a phenomengraphic study of municipal night duty registered nurses' conceptions of reflection. J Clin Nurs2009;18:1460-9.

33. Lambrinou E, Sourtzi P, Kalokerinou A, Lemonidou C. Attitudes and knowledge of the Greek nursing students towards older people. Nurs Educ Today 2009;29:617-22. 